\title{
Preoperative Diagnosis of Intramedullary Spinal Schwannomas
}

\author{
Liang WU, ${ }^{1}$ Ning YAO, ${ }^{1}$ Daxing CHEN, ${ }^{1}$ Xiaofeng DENG, ${ }^{1}$ and Yulun XU ${ }^{1}$ \\ ${ }^{1}$ Department of Neurosurgery, Beijing Tiantan Hospital, \\ Capital Medical University, Beijing, P.R.C.
}

\begin{abstract}
Intramedullary spinal schwannomas are rare benign spinal cord tumors and are easily misdiagnosed because of the imaging characteristics shared with intramedullary glioma. Correct preoperative definitive diagnosis is essential for treatment and prognosis. To improve the preoperative diagnostic strategy, clinical and imaging data of seven patients with intramedullary spinal schwannoma (6 men, mean age 44 years, mean duration of illness 4.2 years) treated in our department between 2003 and 2010 were collected and retrospectively evaluated. The cervical cord was affected in five patients, followed by the thoracic cord in two. All seven cases were misdiagnosed as intramedullary glioma based on the imaging characteristics. Comparison of the clinical features of these 7 patients with those of patients with intramedullary tumors (173 ependymomas and 70 astrocytomas) admitted during the same period revealed significant differences in somatic pain and root pain as the initial symptoms between intramedullary spinal schwannomas and ependymomas $(p=0.005)$ and between intramedullary spinal schwannomas and astrocytomas $(p=0.019)$, but not between ependymomas and astrocytomas $(p=0.175)$. Root or somatic pain as an initial symptom is important for the preoperative diagnosis of intramedullary spinal schwannoma, especially if the imaging characteristics are not entirely specific.
\end{abstract}

Key words: intramedullary schwannoma, spinal cord tumor, preoperative diagnosis

\section{Introduction}

Schwannomas are the most common tumors in the spinal cord. The location is mainly intradural and extramedullary. However, intramedullary schwannomas account for only $0.3-1.5 \%$ of all primary intramedullary tumors. ${ }^{14)}$ Since the earliest report of this disease in 1931, no series of a large number of cases have been published. The imaging characteristics of intramedullary schwannoma usually mimic those of common intraspinal tumors, so the correct preoperative diagnosis may be difficult. Consequently, surgical and medical therapeutic choices may be affected. The present study describes the clinical data of seven patients with these tumors admitted to our department between 2003 and 2010, and examines the preoperative diagnostic strategy for intramedullary spinal schwannoma.

\section{Materials and Methods}

Six men and one woman aged 31 to 61 years at presentation (mean 44 years), with an interval be-

Received December 9, 2010; Accepted June 3, 2011 tween first symptoms and diagnosis of 1-10 years (mean 4.2 years), were diagnosed with intramedullary spinal schwannoma confirmed pathologically. The cervical cord was affected in five patients, followed by the thoracic cord in two. All patients presented with different degrees of sensory and motor dysfunctions. Data were analyzed using the $\chi^{2}$ test, and differences were considered statistically significant if $\mathrm{p}<0.05$.

\section{Results}

The clinical presentations and the results of neurological examinations are summarized in Table 1. On the basis of magnetic resonance (MR) imaging with gadolinium performed preoperatively (Table 2), intramedullary glioma was misdiagnosed in all patients (Fig. 1). Table 3 summarizes the major clinical and radiological findings in this group and in a group of patients with intraspinal gliomas (173 ependymomas and 70 astrocytomas) admitted during the same period. Intramedullary tumors cause similar clinical symptoms at the late stage, so are of no significance in the differential diagnosis. Therefore, only the initial symptoms were described and eval- 


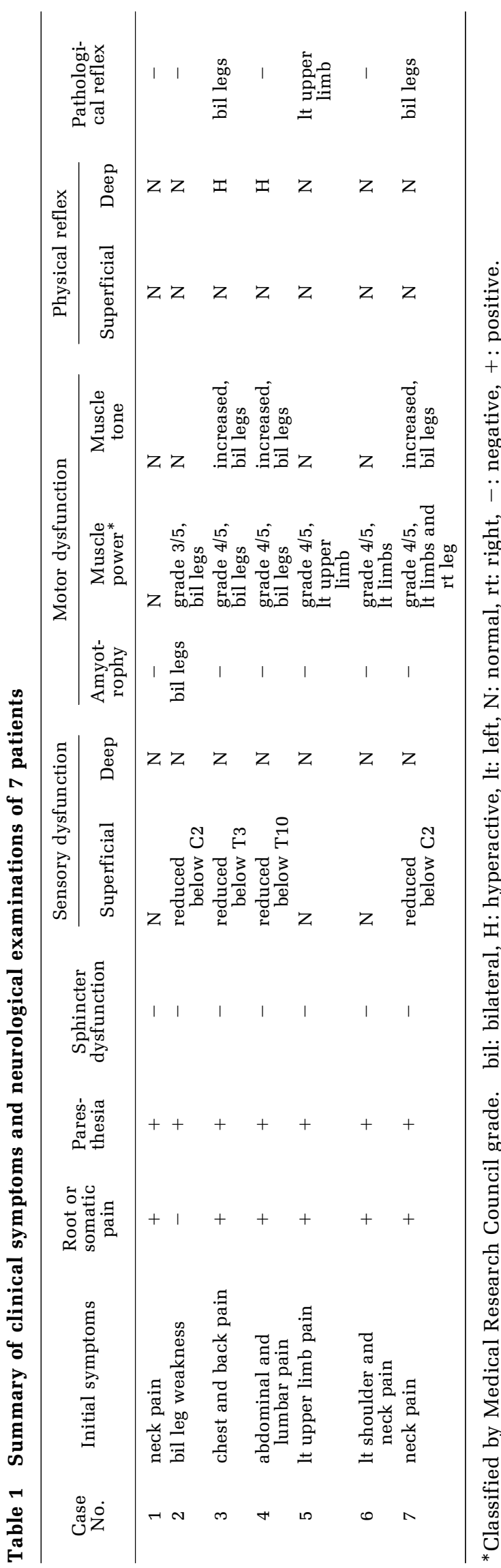

uated. There were statistically significant differences in incidence of somatic pain and root pain as initial symptoms between intramedullary spinal schwannoma and ependymoma $(p=0.005)$ and between intramedullary spinal schwannoma and astrocytoma $(p=0.019)$, but not between ependymoma and astrocytoma $(\mathrm{p}=0.175)$.

MR imaging showed intramedullary schwannomas in our patients as iso- or hypointense on $\mathrm{T}_{1^{-}}$ weighted images and hyperintense or mixed intensity on $\mathrm{T}_{2}$-weighted images. Associated syringomyelia was found above the lesion level in three patients, and the lesions were cystic in four. Gadolinium enhancement was regular in four cases, irregular in two, and circular in one. All tumors were well defined and lacked extramedullary components. No significant difference was found between intramedullary schwannoma and the gliomas.

We applied the modified McCormick classification $^{1,11)}$ (Table 4) to assess neurological function in our patients before surgery, at discharge, at 3 months after surgery, and annually thereafter. Postoperative follow-up periods were 8-84 months (mean 56 months). All patients showed no neurological deterioration and no tumor recurrence (Table 5).

\section{Discussion}

Schwannomas in the spinal cord arise from Schwann cells in the medullary sheath. The origin of intramedullary schwannoma is not the parenchyma of the normal central nervous system (which lacks Schwann cells) and remains controversial. Some theories of etiology ${ }^{4,6,15)}$ suggest that the tumor originates from Schwann cells in the entry zone of the dorsal root, subpial extension of Schwann cells along the perivascular nerve plexus of spinal cord vessels, ectopic neural crest cells during embryogenesis, Schwann cells differentiated from multipotential mesenchymal elements of the central nervous system, and proliferation of Schwann cells associated with trauma or chronic inflammatory disease. In this study, one patient had a tumor at the C2-C3 levels and Arnold-Chiari malformation, so the pathogenesis was hypothesized to be long-term stimulation leading to chronic inflammatory disease. Clearly, various pathogenic mechanisms may cause intramedullary schwannoma.

Intramedullary spinal schwannoma shows no sex predilection. The mean age at presentation is 49.2 years (range 9-75 years). ${ }^{3,6)}$ Evidence of von Recklinghausen's disease is present about $12 \%$ of reported cases. $^{2,5)}$ In our study, intramedullary spinal schwannoma was more common in middle-aged men with prolonged chronic cord compression. The most 
Table 2 Summary of magnetic resonance imaging findings of 7 patients

\begin{tabular}{clrlccc}
\hline Case No. & Site & Size $(\mathrm{mm})$ & Enhancement & \multicolumn{1}{c}{ Margins } & Cystic lesion & Associated syringomyelia \\
\hline 1 & C4-C6 & $11 \times 14 \times 22$ & regular & well demarcated & + & medulla-C4 \\
2 & C6-C7 & $9 \times 12 \times 22$ & circular & well demarcated & + & C2-C5 \\
3 & T3-T5 & $9 \times 10 \times 24$ & irregular & well demarcated & + & C4-T2 \\
4 & T10-T12 & $13 \times 10 \times 33$ & regular & well demarcated & - & - \\
5 & C6-C7 & $9 \times 12 \times 25$ & regular & well demarcated & - & - \\
6 & C2-C3 & $13 \times 16 \times 25$ & regular & well demarcated & - & - \\
7 & C5-C6 & $19 \times 8 \times 13$ & irregular & well demarcated & + & - \\
\hline
\end{tabular}
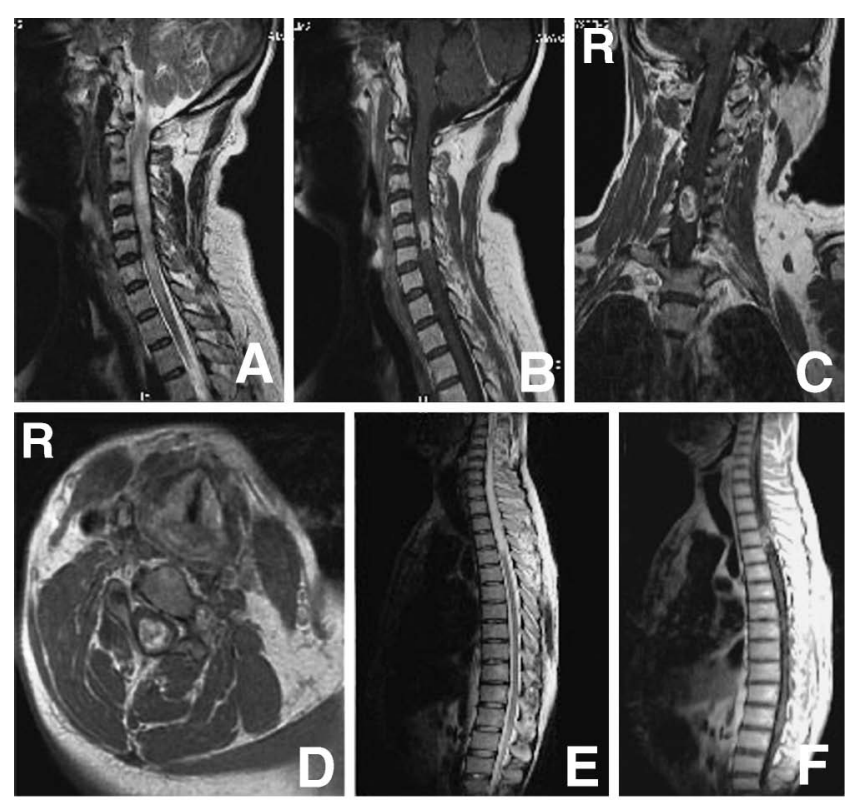

Fig. 1 A-D: Case 7. Preoperative magnetic resonance (MR) images showing an isointense mass with intramedullary edema on the sagittal $T_{2}$-weighted image (A), and an irregularly enhanced, well demarcated mass with a cystic lesion at the $\mathrm{C} 5$ to $\mathrm{C} 6$ levels on sagittal (B), coronal (C), and axial (D) $\mathrm{T}_{1}$-weighted $M R$ images with gadolinium. E, F: Case 3. Preoperative MR images showing a mixed intensity mass with syringomyelia on the sagittal $\mathrm{T}_{2}$-weighted $\mathrm{MR}$ image (E), and an irregularly enhanced, well demarcated mass at the T3 to T5 levels on the sagittal $T_{1}$-weighted $M R$ image with gadolinium (F).

common site was the cervical cord followed by the thoracic cord. On the other hand, gliomas were more common in young patients (age $\leq 18$ years) with rapidly deteriorating symptoms.

The symptoms of intramedullary spinal schwannoma were sensory and motor dysfunctions, which eventually appeared in the late stages of lesion progression. No tumors could be differentiated from common intraspinal tumors. However, somatic and root pain were the initial major complaints in patients with schwannoma, whereas paresthesia or weakness was the major complaint in patients with ependymoma and astrocytoma. Therefore, we believe that this difference between schwannomas and gliomas is important for the differential diagnosis. Otherwise, there was no difference in sex, age, duration of illness, and initial symptoms between extramedullary intradural schwannomas and intramedullary schwannomas, which agrees with the reported findings. ${ }^{9)}$

Tumors extending into the extradural space may compress the nerve root causing pain. However, none of our patients had an extramedullary tumor, but most had root or somatic pain. We suggest that intramedullary schwannoma may originate from Schwann cells in the entry zone of the dorsal nerve root, and the pain occurs as the initial symptom with growth of the tumor. However, the tumor does not grow along the nerve root but extends into the area of the cord where the dorsal nerve root enters the pia mater, so the common symptoms of intramedullary tumors appear gradually during the late stage of the disease. Thus, a detailed description of the patient's symptoms should be obtained because a patient may ignore pain developing early over the prolonged course of the disease.

Many imaging studies have been conducted to characterize intramedullary schwannoma. Intramedullary spinal schwannomas are generally considered to have no radiographic features that distinguish them from intraspinal gliomas. MR imaging shows intramedullary spinal schwannomas are mostly well marginated, iso- or hypointense on $\mathrm{T}_{1}$ weighted images, and hyperintense on $\mathrm{T}_{2}$-weighted images. Associated syringomyelia and cystic degeneration can be found but are uncommon. Intramedullary spinal schwannoma can appear as a well demarcated, highly enhanced, regularly shaped mass. ${ }^{3,5,7,10)}$ In the present study, variations in preoperative MR imaging features presented many difficulties for differential diagnosis. Thus, definitive preoperative diagnosis of intramedullary schwannoma is difficult based only on MR imaging, unless a predominantly extramedullary component or possibly nerve root thickening is visible. ${ }^{8,13)}$ In particular nerve root thickening can explain the root 
Table 3 Summary of intramedullary schwannoma, ependymoma, and astrocytoma

\begin{tabular}{|c|c|c|c|c|c|c|c|c|}
\hline \multirow{2}{*}{$\begin{array}{l}\text { Tumor } \\
\text { (No. of cases) }\end{array}$} & \multirow{2}{*}{$\begin{array}{l}\text { Mean } \\
\text { age } \\
\text { (yrs) }\end{array}$} & \multirow{2}{*}{$\begin{array}{c}\text { Sex } \\
\text { (male: } \\
\text { female) }\end{array}$} & \multirow{2}{*}{$\begin{array}{l}\text { Mean } \\
\text { duration } \\
\text { of illness } \\
\text { (yrs) }\end{array}$} & \multicolumn{4}{|c|}{ Initial symptoms } & \multirow{2}{*}{$\begin{array}{l}\text { Major characteristic radiological } \\
\text { findings on MR imaging }\end{array}$} \\
\hline & & & & $\begin{array}{l}\text { Somatic or } \\
\text { root pain }\end{array}$ & $\begin{array}{c}\text { Motor } \\
\text { weakness }\end{array}$ & $\begin{array}{l}\text { Pares- } \\
\text { thesia }\end{array}$ & $\begin{array}{l}\text { Sphincter } \\
\text { dysfunction }\end{array}$ & \\
\hline Schwannoma (7) & 44 & $6: 1$ & 4.2 & 6 & 1 & 0 & 0 & $\begin{array}{l}\text { well demarcated, } \\
\text { markedly enhanced }\end{array}$ \\
\hline Ependymoma (173) & 35 & $1.3: 1$ & 1.7 & 60 & 46 & 62 & 5 & $\begin{array}{l}\text { mostly at central part of spinal } \\
\text { cord, } \\
\text { sharp margins, } \\
\text { markedly enhanced, } \\
\text { commonly accompanied with } \\
\text { syringomyelia }\end{array}$ \\
\hline Astrocytoma (70) & 33 & $1.9: 1$ & 2.3 & 18 & 30 & 19 & 3 & $\begin{array}{l}\text { mostly at posterolateral part of } \\
\text { spinal cord, } \\
\text { obscure margins, } \\
\text { irregularly enhanced }\end{array}$ \\
\hline
\end{tabular}

MR: magnetic resonance.

Table 4 Modified McCormick classification ${ }^{1,11)}$

\begin{tabular}{cl}
\hline Grade & \multicolumn{1}{c}{ Definition } \\
\hline I $\quad \begin{array}{l}\text { neurologically normal; } \\
\text { gait normal; } \\
\text { normal professional activity } \\
\text { tired after walking several kilometers; } \\
\text { running is impossible, or moderate sensorimotor deficit } \\
\text { does not significantly affect the involved limb; } \\
\text { moderate discomfort in professional activity; } \\
\text { presence of sensorimotor deficit affecting function of } \\
\text { involved limb } \\
\text { mild to moderate gait difficulty; } \\
\text { severe pain or dysesthetic syndrome impairs quality of life; } \\
\text { independent function and ambulation maintained } \\
\text { more severe neurological deficit; } \\
\text { requires cane and/or brace for ambulation or maintains } \\
\text { significant bil upper extremity impairment; } \\
\text { may or may not function independently } \\
\text { severe neurological deficit; } \\
\text { requires wheelchair or cane and/or brace with bil upper } \\
\text { extremity impairment; } \\
\text { usually not independent }\end{array}$ \\
\hline
\end{tabular}

or somatic pain experienced as the initial symptom by most of our patients. However, no association of nerve root thickening with the presence of tumor was established in our patients and thickened spinal nerve root associated with tumors is not definitely found in the literature. Therefore, we believe that this imaging feature is highly specific but uncommon. Consequently, the role of MR imaging is limited in the diagnosis of intramedullary schwannoma.

Preoperative diagnosis of intraspinal neoplasm will help establish the optimum medical and surgical treatment and the prognosis. Chronic compression is the main pathogenic mechanism in intramedullary schwannomas and the tumors are usually benign and well marginated, so tumor removal based on protection of spinal functions is realizable if tumorfree margins are confirmed by intraoperative frozen sections. In our cases, laminectomy was performed, and the tumor surface was easily found intraoperatively. The tissues in 4 cases of intramedullary tumor showed varying degrees of adhesion to the dorsal root, but total removal was achieved using microsurgical techniques (Fig. 2). Therefore, complete resection is advised, and relatively favorable prognosis may be possible, even though the preoperative symptom is severe. However, if the tumor is in the conus medullaris, or densely adherent to neural tissue, subtotal removal of the tumor is advised to avoid unacceptable operative complications. ${ }^{12)}$

In clinical diagnosis, overemphasis of imaging results and underemphasis of the importance of clinical features should be avoided. Misdiagnosis of intramedullary schwannoma as intraspinal glioma may lead to inappropriate treatment (i.e. conservative therapy or even no treatment) rather than the appropriate treatment and cure by surgery. Although intramedullary spinal schwannoma is still difficult to identify preoperatively, the accuracy of identification can be improved by comprehensive analysis of clinical features and radiographic results.

The present case series and review suggest that intramedullary spinal schwannoma should be considered in the differential diagnosis of a middle-aged male patient with prolonged somatic or root pain as the initial symptom but without signs of severe neural damage, if the site of the lesion is in the cervical or thoracic intramedullary cord, and the tumor has sharp margins and marked enhancement on MR imaging.

\section{References}

1) Aghakhani N, David P, Parker F, Lacroix C, Benoudiba F, Tadie M: Intramedullary spinal ependymomas: analysis of a consecutive series of 82 adult cases with particular attention to patients with no preoperative neurological deficit. Neurosurgery 62: 1279-1285, 2008

2) Bhayani R, Goel A: Multiple intramedullary schwannomas-case report. Neurol Med Chir (Tokyo) 36: 
Table 5 Summary of preoperative, postoperative, and final assessment of neurological function of 7 patients

\begin{tabular}{|c|c|c|c|c|}
\hline \multirow{2}{*}{ Case No. } & \multicolumn{3}{|c|}{ McCormick grade } & \multirow{2}{*}{$\begin{array}{l}\text { Follow-up period } \\
\text { (mos) }\end{array}$} \\
\hline & Preoperative & Postoperative & Last follow up & \\
\hline 1 & I & I & I & 84 \\
\hline 2 & II & II & I & 82 \\
\hline 3 & $\mathrm{Ib}$ & I & I & 73 \\
\hline 4 & $\mathrm{Ib}$ & $\mathrm{Ib}$ & I & 70 \\
\hline 5 & $\mathrm{Ib}$ & I & I & 66 \\
\hline 6 & $\mathrm{Ib}$ & $\mathrm{Ib}$ & I & 12 \\
\hline 7 & $\mathrm{Ib}$ & $\mathrm{I}$ & I & 8 \\
\hline
\end{tabular}

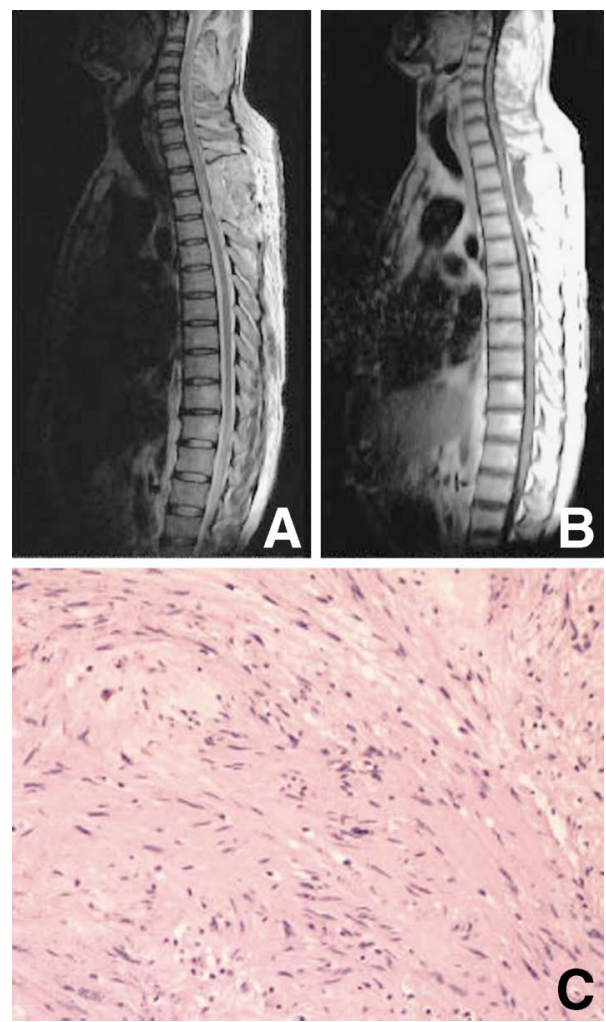

Fig. 2 Case 3. A: Sagittal $T_{2}$-weighted magnetic resonance (MR) image showing the syringomyelia relieved after surgery. B: Sagittal $\mathrm{T}_{1}$-weighted $\mathrm{MR}$ image with gadolinium revealing total excision of the tumor. C: Photomicrograph of the tumor tissue illustrating elongated bipolar spindle cells with arrangement of nuclei in palisades pattern, typical of Antoni A tissue, and mixture with Antoni $B$ tissue. Hematoxylin and eosin stain, original magnification $\times 200$.

466-468, 1996

3) Binatli O, Ersahin Y, Korkmaz O, Bayol U: Intramedullary schwannoma of the spinal cord: a case report and review of the literature. J Neurosurg Sci 43: 163-168, 1999

4) Brown KM, Dean A, Sharr MM: Thoracic intramedullary schwannoma. Neuropathol Appl Neurobiol 28: 421-424, 2002
5) Colosimo C, Cerase A, Denaro L, Maira G, Greco R: Magnetic resonance imaging of intramedullary spinal cord schwannomas: report of two cases and review of the literature. J Neurosurg 99: 114-117, 2003

6) Kim SD, Nakagawa H, Mizuno J, Inoue T: Thoracic subpial intramedullary schwannoma involving a ventral nerve root: a case report and review of the literature. Surg Neurol 63: 389-393, 2005

7) Kodama Y, Terae S, Hida K, Chu BC, Kaneko K, Miyasaka K: Intramedullary schwannoma of spinal cord: report of two cases. Neuroradiology 43: 567571,2001

8) Kono K, Inoue Y, Nakamura H, Shakudo M, Nakayama K: MR imaging of a case of a dumbbell-shaped spinal schwannoma with intramedullary and intradural-extramedullary components. Neuroradiology 43: 864-867, 2001

9) Li J, Li X, Liu L, Yang B, Liu C, Yang J, Wang G: [Microsurgical treatment of intraspinal neurilemmomas: report of 342 cases]. Chinese Journal of NeuroOncology 1: 17-21, 2007 (Chinese)

10) Maira G, Amante P, Denaro L, Mangiola A, Colosimo C: Surgical treatment of cervical intramedullary spinal cord tumors. Neurol Res 23: 835-842, 2001

11) McCormick PC, Torres R, Post KD, Stein BM: Intramedullary ependymoma of the spinal cord. J Neurosurg 72: 523-532, 1990

12) Ohtonari T, Nishihara N, Ota T, Ota S, Koyama T: Intramedullary schwannoma of the conus medullaris complicated by dense adhesion to neural tissue. Neurol Med Chir (Tokyo) 49: 536-538, 2009

13) Parmar HA, Ibrahim $M$, Castillo $M$, Mukherji SK: Pictorial essay: diverse imaging features of spinal schwannomas. J Comput Assist Tomogr 31: 329-334, 2007

14) Riffaud L, Morandi X, Massengo S, Carsin-Nicol B, Heresbach N, Guegan Y: MRI of intramedullary spinal schwannomas: case report and review of literature. Neuroradiology 42: 275-279, 2000

15) Ross DA, Edwards MS, Wilson CB: Intramedullary neurilemomas of the spinal cord: Report of two cases and review of the literature. Neurosurgery 19: 458464, 1986

Address reprint requests to: Yulun Xu, MD, Department of Neurosurgery, Beijing Tiantan Hospital, Capital Medical University, No.6 Tiantan Xili, Chongwen District, Beijing 100050, China.

e-mail:xuhuxi@sina.com 